\title{
Stability and Performance Evaluation of Advanced Bread Wheat (Triticum aestivum L.) Genotypes in Optimum Areas of Ethiopia
}

\section{Abebe Delesa $\varangle \oplus$, Gadisa Alemu, Negash Geleta, Alemu Dabi, Habtemariyam Zegeye, Tafesse Solomon, Rut Duga, Dawit Asnake, Zerihun Tadesse, Bayisa Asefa and Abebe Getamesay}

Ethiopian Institute of Agricultural Research, Kulumsa Agricultural Research Center, Asella, Ethiopia

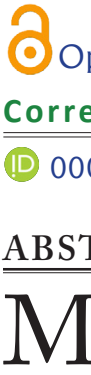

Open Access

Corresponding $\times$ abeararsa@gmail.com

0000-0002-9725-1126

\begin{abstract}
$\mathrm{M}$ ulti-environment trials were carried out at 11 locations in different wheat growing zones of Ethiopia during 2017-18 and 2018-19 to identify high yielding, stable, biotic and abiotic stresses resistant varieties with improved quality traits for commercial release. Twenty-eight advanced bread wheat genotypes have been evaluated against two released bread wheat varieties. The experiment was laid out using alpha lattice design with three replications. Nine stability models were employed in order to assess stability and performance of 28 advanced bread wheat genotypes across 18 diverse environments. Combined analysis of variance for grain yield has revealed that the environments, the genotypes and GEI effects were significantly different ( $\mathrm{p}<0.001)$. Environments, GEI and Genotypic effects accounted for $71.99 \%, 22.97 \%$ and $5.03 \%$ of the total grain yield variation, respectively. Significant GEI showed variable performance of genotypes across environments. Eight advanced bread wheat genotypes namely ETBW8595, ETBW8668, ETBW8751, ETBW8991, ETBW8996, ETBW9547, ETBW9553 and ETBW9554 produced grain yield of more than $5.0 \mathrm{t} \mathrm{ha}^{-1}$, indicating their superior yielding potential. ETBW8595, ETBW8668, ETBW8751, ETBW8991 and ETBW9554 were found the most stable bread wheat genotypes as confirmed by five to eight stability models. ETBW8751, ETBW8991 and ETBW9554 were highest yielding, stable, adaptable, resistant and moderately resistant to prevailing stem and yellow rust diseases. Thus, these three genotypes were the most promising advanced bread wheat genotypes to be verified and released in Ethiopia. These promising bread wheat genotypes can be included in multipurpose bread wheat crossing blocks in order to correct shortcomings of commercial varieties.
\end{abstract}

KEYWORDS: Bread wheat, GEI, stability, yield

Citation (VANCOUVER): Delesa et al., Stability and Performance Evaluation of Advanced Bread Wheat (Triticum aestivum L.) Genotypes in Optimum Areas of Ethiopia. International Journal of Bio-resource and Stress Management, 2022; 13(1), 69-80. HTTPS://DOI. ORG/10.23910/1.2022.2732.

Copyright: (c) 2022 Delesa et al. This is an open access article that permits unrestricted use, distribution and reproduction in any medium after the author(s) and source are credited.

Data Availability Statement: Legal restrictions are imposed on the public sharing of raw data. However, authors have full right to transfer or share the data in raw form upon request subject to either meeting the conditions of the original consents and the original research study. Further, access of data needs to meet whether the user complies with the ethical and legal obligations as data controllers to allow for secondary use of the data outside of the original study.

Conflict of interests: The authors have declared that no conflict of interest exists.

RECEIVED on $09^{\text {th }}$ November 2021 RECEIVED in revised form on $05^{\text {th }}$ January 2022 ACCEPTED in final form on $25^{\text {th }}$ January 2022 PUBLISHED on $31^{\text {st }}$ January 2022 


\section{INTRODUCTION}

$\mathrm{W}$ Theat is one of the first domesticated food crops and has been the basic staple food since antiquity (Curtis et al., 2002; Charmet, 2011; Haas et al., 2018). The economic, commercial and industrial importance of wheat and its contribution to the diets of humans and livestock cannot be disputed (Shewry and Sandra, 2015). Wheat is the leading source of dietary calories and proteins (Asghar et al., 2011; Shiferaw et al., 2013). The increasing demand for wheat in the world emanates from its unique ability to make different food products, easy of grain storage, easy of transportation, easy of converting grain in to flour and increased consumption of these products due to population growth, urbanization, industrialization and westernization.

Wheat is widely produced in the highlands and mid-altitudes of Ethiopia. In Ethiopia, wheat is among major important cereal crop occupying 1.79 million hectares of land with total production of 5.32 million tonnes and productivity of $2.97 \mathrm{t} \mathrm{ha}^{-1}$ (CSA, 2020). In spite of presence of wide agroecologies suitable for wheat production; elasticity of wheat to be grown from extreme lowlands to highlands; increased demand for wheat due to population growth, urbanization, expansion of agro-industries; wheat production is left behind by 25 to $30 \%$ to its demand in Ethiopia (Hodson et al., 2020). In developing countries wheat demand will increase dramatically by 2050 (Roesgrant and Agcaoili, 2010; Nelson et al., 2010; Shiferaw et al., 2013). Presence of significant GEI (genotype by environment interaction) (Gadisa and Abebe, 2020; Gadisa et al., 2021; Verma and Singh, 2021); lack of high yielding and stable varieties suitable to diverse agro-ecologies; biotic stresses; abiotic stresses; poor cultural practices; mono-cropping and socio-economic constraints are wheat production challenges in Ethiopia (Habte et al., 2014; Hodson et al., 2020).

Plant breeders are highly concerned with the development and release of high yielding, stable and stresses resistant crop varieties (Akcura et al., 2006). A stable genotype is the one possessing constant performance irrespective of changes in environmental conditions (Becker and Leon, 1988; Fasahat et al., 2015; Temesgen et al. 2015). A fruitfully developed new variety should be stable and broadly adaptable over a wide ranges of environments on top of high yielding potential (Akcura et al., 2006). Evaluating stability of performance and range of adaptation has become increasingly important for any breeding programs. The GEI study is especially important in countries with various agro-ecologies (Fasahat et al., 2015) like Ethiopia. The study of GEI is important in order to develop a variety for wide adaptation or exploit specifically adapted one. Hence, a large number of statistical procedures have been developed to enhance breeders understanding of GEI and stability of genotypes cross environments.

Several varieties of bread wheat have been released for large scale production in Ethiopia (MoANR, 2016; Hodson, et al., 2020). However, their high yielding potential and rusts resistance ability will not last long mainly due to stem and yellow rusts epidemic (Olivera et al., 2015; Singh et al., 2015; Tolemariam et al., 2018). Yellow and stem rust diseases continued as the major biotic threat to wheat production in Ethiopia. Nowadays, Ethiopia has reached on stage where bread wheat cannot be produced without application of fungicides, especially in wheat belt Zones like Arsi, West Arsi and Bale Zones. Hence, Ethiopian Wheat Research Program introduces thousands of bread wheat germplasms annually from International Research Institutes and evaluate germplasms under quarantine blocks and in series of yield trials over locations and years. Therefore, the objective of the present study is to identify high yielding, stable and rust diseases resistant bread wheat genotypes and recommend the most promising ones for verification and release.

\section{MATERIALS AND METHODS}

\subsection{Planting materials and test locations}

Twenty-eight advanced bread wheat genotypes were evaluated against two checks (Wane and Hidase) at 11 locations or 18 environments representing different wheat growing zones of Ethiopia in 2017-18 and 201819 cropping seasons. Sowing and harvesting of evaluated materials were carried out from mid-June to mid-July and from November to December, respectively. Description of 11 test locations and advanced bread wheat genotypes were presented in Tables 1 and 2, respectively.

\subsection{Experimental design and layout}

Alpha lattice design with three replications was employed in order to evaluate the treatments. Each entry was planted at a rate of $125 \mathrm{~kg} \mathrm{ha}^{-1}$ in a plot of six rows of $20 \mathrm{~cm}$ spacing and $2.5 \mathrm{~m}$ long. Fertilizer application and other crop management practices were applied as per the local recommendations for each testing locations. Data on different agronomic and quality traits such as days to $50 \%$ heading, days to $90 \%$ maturity, plant height, 1000-kernal weight (TKW), hectoliter weight (HLW), diseases, grain yield were recorded.

\subsection{Statistical methods}

The combined analysis of variance was first carried out across the test locations. The statistics used to assess the stability and adaptability of genotypic mean yield were coefficient of variation (CV) for each genotype as used by Francis and Kannenberg (1987), the genotypic eccovalence as proposed by Wricke (1962), the GE interaction variance or stability 


\begin{tabular}{|c|c|c|c|c|c|c|}
\hline \multirow{2}{*}{ Location } & \multicolumn{2}{|c|}{ Geographic position } & \multirow[t]{2}{*}{ Altitude } & \multicolumn{2}{|c|}{ Temperature $\left({ }^{\circ} \mathrm{C}\right)$} & \multirow[t]{2}{*}{ Rainfall (mm) } \\
\hline & Latitude & Longitude & & Min. & Max. & \\
\hline Adet & $11^{\circ} 16^{\prime} \mathrm{N}$ & $37^{\circ} 29^{\prime} \mathrm{E}$ & 2216 & 9.2 & 25.5 & 1250 \\
\hline Asasa & $07^{\circ} 07^{\prime} 228^{\prime \prime} \mathrm{N}$ & $39^{\circ} 11^{\prime} 932^{\prime \prime} \mathrm{E}$ & 2360 & 5.8 & 23.6 & 620 \\
\hline Arsi Robe & $7^{\circ} 53^{\prime} 02^{\prime \prime}$ & $39^{\circ} 37^{\prime} 40^{\prime \prime}$ & 2420 & 6.0 & 22.1 & 796 \\
\hline Areka & $7^{\circ} 325^{\prime \prime} \mathrm{N}$ & $37^{\circ} 40^{\prime} 52^{\prime \prime} \mathrm{E}$ & 2230 & - & - & 1290 \\
\hline Awelgera & - & - & - & - & - & - \\
\hline Bekoji & $07^{\circ} 32^{\prime} 629^{\prime \prime} \mathrm{N}$ & $39^{\circ} 15^{\prime} 360^{\prime \prime} \mathrm{E}$ & 2780 & 7.9 & 18.6 & 1010 \\
\hline Debrezeyit & $08^{\circ} 38^{\prime} 08^{\prime \prime} \mathrm{N}$ & $38^{\circ} 30^{\prime} 15^{\prime \prime} \mathrm{E}$ & 2050 & NA & NA & 900 \\
\hline Enawari & $9^{\circ} 53^{\prime} 0.0 " \mathrm{~N}$ & $39^{\circ} 09^{\prime} 00.0 " \mathrm{E}$ & 2650 & NA & NA & 878 \\
\hline Holeta & $09^{\circ} 03^{\prime} 414^{\prime \prime} \mathrm{N}$ & $38^{\circ} 30^{\prime} 436^{\prime \prime} \mathrm{E}$ & 2400 & 6.1 & 22.4 & 976 \\
\hline Kulumsa & $08^{\circ} 01^{\prime} 10^{\prime \prime} \mathrm{N}$ & $39^{\circ} 09^{\prime} 11^{\prime \prime E}$ & 2200 & 10.5 & 22.8 & 820 \\
\hline Shambu & 9³4' 0"N & $37^{\circ} 6^{\prime} 0 " \mathrm{E}$ & 2503 & - & - & - \\
\hline
\end{tabular}

-: Data not available

Table 2. List of advanced bread wheat genotypes evaluated in 18 environments in Ethiopia and their pedigrees

Genotype Genotype Pedigree

id

$1 \quad$ Wane Check

2 ETBW 8751 SUP152//ND643/2*WBLL1

3 ETBW 8858 SWSR22T.B./2*BLOUK \#1//WBLL1*2/KURUKU

4 ETBW 8870 WAXWING*2/TUKURU//KISKADEE \#1/3/FRNCLN

5 ETBW 8802 CHAM-4/SHUHA'S'/6/2*SAKER/5/RBS/ANZA/3/KVZ/HYS//YMH/TOB/4/ BOW'S"

6 ETBW 8991 SUP152//ND643/2*WBLL1

7 ETBW 8862 C80.1/3*BATAVIA//2*WBLL1/3/C80.1/3*QT4522//2*PASTOR/4/WHEAR/SOKOLL

8 ETBW 8804 TURACO/CHIL/6/SERI 82/5/ALD'S'/4/BB/GLL//CNO67/7C/3/KVZ/TI

9 ETBW 8996 FALCIN/AE.SQUARROSA (312)/3/THB/CEP7780//SHA4/LIRA/4/FRET2/5/ DANPHE \#1/11/CROC_1/AE.SQUARROSA (213)//PGO/10/ATTILA*2/9/KT/ BAGE//FN/U/3/BZA/4/TRM/5/ALDAN/6/SERI/7/VEE\#10/8/OPATA

10 ETBW 8583 MINO/898.97/4/PFAU/SERI.1B//AMAD/3/KRONSTAD F2004

11 ETBW 8668 BAVIS*2/3/ATTILA/BAV92//PASTOR

12 ETBW 8595 BAVIS*2/3/ATTILA/BAV92//PASTOR

13 ETBW 8684 PASTOR//HXL7573/2*BAU/3/WBLL1/4/1447/PASTOR//KRICHAUFF

14 ETBW 9486 FRANCOLIN \#1/3/PBW343*2/KUKUNA*2//YANAC/4/KINGBIRD \#1//INQALAB 91*2/TUKURU

15 ETBW 9547 MUTUS*2/AKURI//MUTUS*2/TECUE \#1

16 ETBW 9548 REEDLING \#1//KFA/2*KACHU

17 ETBW $9549 \mathrm{KFA} / 2 * \mathrm{KACHU} / 3 / \mathrm{KINGBIRD}$ \#1//INQALAB 91*2/TUKURU/4/KFA/2*KACHU

18 ETBW $9550 \mathrm{KFA} / 2 * \mathrm{KACHU}^{*} 2 / / \mathrm{WAXBI}$

19 ETBW 9551 KFA/2*KACHU/4/KACHU \#1//PI 610750/SASIA/3/KACHU/5/KFA/2*KACHU 


\begin{tabular}{lll}
\hline $\begin{array}{l}\text { Genotype } \\
\text { id }\end{array}$ & Genotype & Pedigree \\
\hline 20 & ETBW 9552 & KACHU \#1/4/CROC_1/AE.SQUARROSA (205)//BORL95/3/2*MILAN/5/ \\
& & KACHU/6/KFA/2*KACHU \\
21 & ETBW 9553 & MURGA/KRONSTAD F2004/3/KINGBIRD \#1//INQALAB 91*2/TUKURU \\
22 & ETBW 9554 & SAUAL/MUTUS/6/CNO79//PF70354/MUS/3/PASTOR/4/BAV92*2/5/FH6-1-7/7/ \\
& & CNO79//PF70354/MUS/3/PASTOR/4/BAV92*2/5/FH6-1-7 \\
23 & ETBW 9555 & KFA/2*KACHU/5/WBLL1*2/4/BABAX/LR42//BABAX/3/BABAX/LR42//BABAX/6/ \\
& & KFA/2*KACHU \\
24 & ETBW 9556 & SOKOLL/3/PASTOR//HXL7573/2*BAU/4/PARUS/PASTOR \\
25 & ETBW 9557 & SOKOLL/WBLL1/4/D67.2/PARANA 66.270//AE.SQUARROSA (320)/3/ \\
& & CUNNINGHAM \\
26 & ETBW 9558 & BABAX/LR42//BABAX/3/ER2000/5/ATTILA/4/WEAVER/TSC//WEAVER/3/ \\
& & WEAVER/6/KA/NAC//TRCH \\
27 & ETBW 9559 & CHIBIA//PRLII/CM65531/3/MISR 2*2/4/HUW234+LR34/PRINIA//PBW343*2/ \\
& & KUKUNA/3/ROLF07 \\
28 & ETBW 9560 & CHWINK/GRACKLE \#1//FRNCLN \\
29 & ETBW 9561 & TRAP\#1/BOW/3/VEE/PJN//2*TUI/4/BAV92/RAYON/5/KACHU\#1*2/6/KINGBIRD \\
& & \#1 \\
30 & Hidase & Check \\
\hline
\end{tabular}

variance as suggested by Shukla, (1972), Superiority Index (PI) measure as used by Lin and Binns (1988), conventional linear regression coefficient as suggested by Finlay and Wilkinson (1963), deviation from conventional regression mean square (Eberhart and Russell, 1966), coefficient of determination (Pinthus, 1973), adjusted linear regression coefficient and deviation as proposed by Perkins and Jink (1968), nonparametric stability statistics (Nassar and Huehn, 1987) and the Additive Main effect and the Multiplicative Interaction effect (AMMI) (Yan, 2011). A comprehensive free software has become available, which calculates the most parametric and nonparametric stability statistics (Pacheco et al., 2016) which is used to calculate stability statistics.

\section{RESULTS AND DISCUSSION}

$\mathrm{T}$ he AMMI ANOVA for grain yield of the 30 bread wheat genotypes across the 18 environments indicated that the environments, the genotypes and GEI effects were significantly different $(p<0.001)$. Several authors (Kaya et al., 2002; Asrat et al., 2009; Farshadfar and Sadeghi, 2014.; Yasin et al., 2014; Verma et al., 2015; Jeberson et al., 2017) reported similar findings suggesting the existence of wide variability among environments, among genotypes and the possibility of selecting stable genotypes. The present results revealed that the environments which accounted for $71.99 \%$ of the total grain yield variation, highly and significantly influenced the yielding ability of the bread wheat genotypes. A large grain yield variation, explained by environments, indicated that the environments were diverse and a major part of variation in grain yield can be resulted from environmental changes (Table 3), followed by genotype $\mathrm{x}$ environments interaction and genotypic effects accounting for $22.97 \%$ and $5.03 \%$, respectively. Similar investigations have been reported by several authors on different crops including wheat (Kaya et al., 2002; Farshadfar and Sadeghi, 2014.; Verma et al., 2015; Jeberson et al., 2017; Dawit et al., 2017; Gadisa et al., 2021), soybean (Asrat et al., 2009) and field pea (Yasin et al., 2014) indicating environments and interaction effects are much more than the effect of genotypes. In the present study the GEI effect is 4.6 times larger than the genotypic effects indicating the existence of differential response of the genotypes to changes in growing environments and the discriminating ability of the environments.

\subsection{AMMI analysis}

Highly significant environments, genotypes and $\mathrm{GxE}$ interaction explained $71.99 \%, 5.03 \%$ and $22.97 \%$ of the total sum of squares, respectively (Table 3 ). The significant $\mathrm{GE}$ interaction sum of squares is further partitioned into 18 interaction principal component axes (IPCAs), of which the first six are significant (Table 3). These six IPCAs showed $80 \%$ of variation of the total sum of squares due to the interaction. The first four IPCAs explained 25.26\%, $18.07 \%, 14.57 \%$ and $8.26 \%$, of the $\mathrm{GE}$ interaction variation, respectively. Similar to the present investigation, 
Table 3: AMMI analysis of variance for grain yield of 30 bread wheat genotypes evaluated across 18 environments in Ethiopia in 2017/18 and 2018/19

\begin{tabular}{lccccc}
\hline & DF & SS & MS & PROBF & \% explained \\
\hline ENV & 17 & $3.56 \mathrm{E}+09$ & $2.09 \mathrm{E}+08$ & 0 & 71.99555 \\
GEN & 29 & $2.48 \mathrm{E}+08$ & 8568297 & 0 & 5.03137 \\
ENV ${ }^{*}$ GEN & 493 & $1.13 \mathrm{E}+09$ & 2301330 & 0 & 22.97308 \\
PC1 & 45 & $2.56 \mathrm{E}+08$ & 5685769 & 0 & 25.26421 \\
PC2 & 43 & $1.83 \mathrm{E}+08$ & 4256253 & 0 & 18.07174 \\
PC3 & 41 & $1.48 \mathrm{E}+08$ & 3598693 & 0 & 14.5691 \\
PC4 & 39 & 83677181 & 2145569 & 0.00477 & 8.26249 \\
PC5 & 37 & 70252240 & 1898709 & 0.02668 & 6.93688 \\
PC6 & 35 & 67737386 & 1935354 & 0.02412 & 6.68856 \\
Residuals & 1065 & $1.36 \mathrm{E}+09$ & 1275715 & NA & 0 \\
\hline
\end{tabular}

the first two PCs explained $46.62 \%$ of the total variation, in which the contribution of PC1 was $27.94 \%$ and that of PC2 was $18.68 \%$ (Singh et al., 2019). Verma et al. (2015) and Jeberson et al. (2017) obtained similar results by evaluating 17 and 11 wheat genotypes in eight locations, respectively. The extracted IPCAs are capable of providing adequate information on the interaction effects but their degree decreases from the first to the last IPCAs. Thus, the first two best explain the interaction sums of square (Zobel et al., 1988; Gauch, 2006). Hence, data set obtained by evaluating 30 bread wheat genotypes across 18 environments was best predicted by using the first two IPCAs. The closer the IPCA scores approximate to zero the stable the genotype across all environments (Purchase, 1997). The greater the values, either positive or negative, the unstable the genotype is. In the biplot display system, either main effects and IPCA-1, or IPCA-1 and IPCA-2 are commonly used as abscissa and ordinates (Zobel et al., 1988).

Based on the present results ETBW9548 (G16), ETBW9550 (G18), ETBW9552 (G20), ETBW9554 (G22) and ETBW9558 (G26) are highly stable bread wheat genotypes for their IPC1 score was very close to zero indicating their low response to interaction and wider adaptation to the test environments. Likewise, bread wheat genotypes like ETBW8751 (G2), ETBW8802 (G5), ETBW8804 (G8), ETBW8996 (G9), ETBW8583 (G10), ETBW8684 (G13), ETBW9553 (G21) and ETBW9555 (G23) are stable for their relative IPC1 scores were closer to zero (Figure, 1). Among tested genotypes ETBW8751 (G2), ETBW8996 (G9), ETBW9553 (G21) and ETBW9554 (G22) were stable as well as highest yielding, as they produced grain yield that ranged from 5.1 $\mathrm{t} \mathrm{ha} \mathrm{h}^{-1}$ to $5.4 \mathrm{t} \mathrm{ha}^{-1}$. Thus, these genotypes were the most promising ones. On the other hand, ETBW8870 (G4), ETBW8991 (G6), ETBW8862 (G7), ETBW8668 (G11),

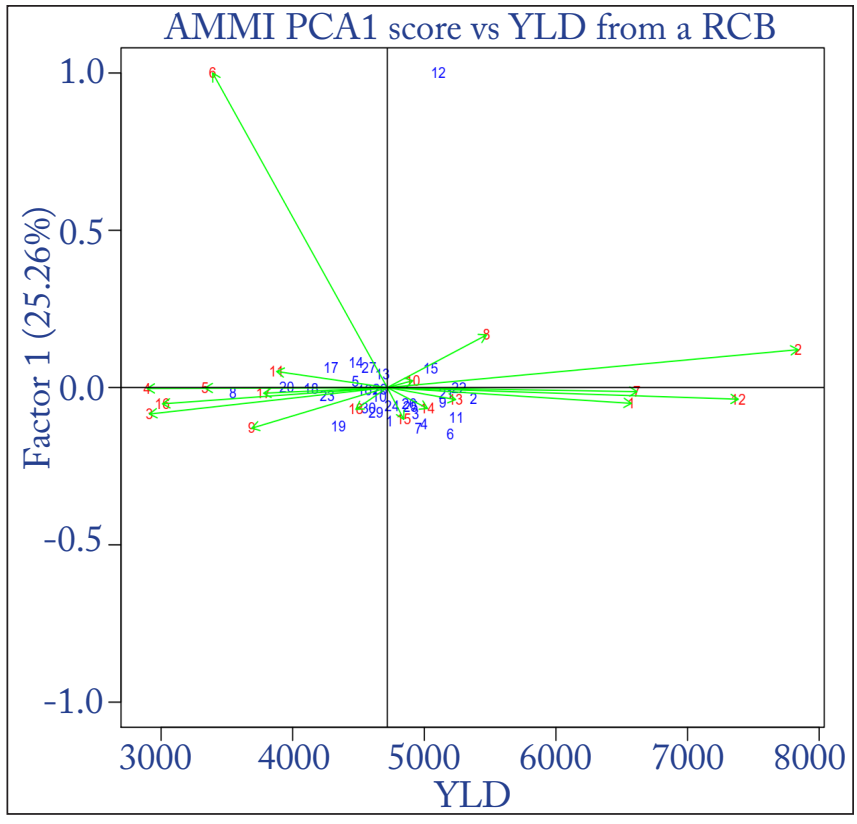

Figure 1: AMMI-1 biplot showing the main effects vs stability (IPC1) view of both genotypes and environments on seed yield. Abbrevations of genotypes are as shown on Table 2. Where, Environment 1 (E1)=Asasa-2017; E2=Kulumsa-2017; E3=Arsi Robe-2017; E4=Bekoji-2017; E5=Enewari 2017; E6=Areka-2017; E7=Awelgera-2017; E 8=Debrezeyit -2017 ; E9=Arsi Robe-2018; E10=Asasa-2018; E11=Bekoji-2018; E12=Kulumsa-2018; E13=Awelgera-2018; E14=Holeta-2018; E15=Adet-2018; E16=Areka-2018; E17=Enewari-2018;E18=Shambu-2018.

ETBW9486 (G14), ETBW9547 (G15), ETBW9549 (G17) and ETBW9551 (G19) were unstable genotypes. Besides, ETBW9486 (G14), ETBW9549 (G17) and ETBW9551 (G19) were poor yielders. ETBW8595 (G12) was exceptionally highly unstable (Figure 1). ETBW8595 (G12), which is the most unstable genotype was specifically 
adapted to Asasa-2017 (E1), Kulumsa-2017 (E2), Awelgera-2017 (E7), Debrezeit-2017 (E8), Kulumsa-2018 (E12) and Awelgera-2018 (E13) (Figure 1).

\subsection{Francis and Kannenberg's stability model}

Francis and Kannenberg (1978) suggested that the combined use of coefficient of variation $(\mathrm{CV})$ and mean yield could be used as a measure of stability. The coefficient of variation is plotted against the mean yield across environments for every genotype. Genotypes with a low $\mathrm{CV}$ and high yield are regarded as most stable and desirable. In the present study bread wheat genotypes including ETBW8595, ETBW8668, ETBW8751, ETBW8991, ETBW8996 and ETBW9554 were the most stable and desirable as they showed the lowest variation and produced highest seed yield that ranged from 5.1 to $5.4 \mathrm{t} \mathrm{ha}^{-1}$ (Table 4). Likewise, Gadisa et al. (2021) identified eight bread wheat varieties as stable and superior yielders by using conventional $\mathrm{CV}$ as stability model. Besides, Abd El-Shafi et al. (2014) identified five stable bread wheat genotypes by evaluating 10 bread wheat genotypes across eight environments. Furthermore, Akcura et al. (2006) reported similar results. On the other hand, ETBW9486, ETBW9547, ETBW9548, ETBW9550, ETBW9551, ETBW9552, ETBW9559 and Hidase were the most interactive or unstable and low yielding. Contrary to the present findings Yaghotipoor et al. (2017) identified four highest yielding bread wheat genotypes as unstable by using $\mathrm{CV}$ as stability model.

\subsection{Eberhart and Russell's stability model}

Eberhart and Russell (1966) suggested that optimal yield stability measured through regression approaches would be represented by a variety with high mean yield, moderate to high $\mathrm{Bi}$ value, or responsive to favorable environmental conditions, and with deviation from regression $\left(\mathrm{S}^{2} \mathrm{di}\right)$ as low as possible. The linear (bi) and non linear ( $\mathrm{s}^{2} \mathrm{di}$ ) components of GEI shall be considered to judge the stability of genotypes across wide range of environments (Akura et al., 2005). A regression coefficient (bi) approximating unity together with $\mathrm{s}^{2}$ di value of zero indicates average stability (Eberhart and Russell, 1966). Regression values above unity indicate genotypes with higher sensitivity to environmental changes (below average stability). Such genotypes are specifically adapted to higher yielding environments. On the other hand, regression coefficient below unity indicates that the genotypes are resistant to environmental changes (above average stability) and such genotypes are specifically adaptable to low yielding environments. In the current study regression coefficients (bi values) ranged from 0.688 to 1.159 for grain yield representing different responses of genotypes to environmental changes. Based on the present findings the following genotypes: ETBW8802, ETBW8804, ETBW8996, ETBW9547 and ETBW9560 recorded bi value below unity (Table 4). Thus, these genotypes showed above average stability and therefore specifically adaptable to low yielding environments. On the other hand, bread wheat genotypes like ETBW8858, ETBW8862, ETBW8870, ETBW9486 and ETBW9548 recorded bi value above unity and were therefore showed below average stability and were therefore specifically adaptable to high yielding environments and/or were sensitive to environmental changes. The high yielding or favorable environments are those where farmers adopt good agronomic practices along with high technology, have high soil fertility and favorable climatic conditions (Ferreira et al., 2006). ETBW8583, ETBW8595, ETBW8684, ETBW8991, ETBW9554 and ETBW9561 recorded bi value of one and were therefore showed average adaptability. Considering both bi and $\mathrm{S}^{2} \mathrm{di}$ parameters bread wheat genotypes namely ETBW8583, ETBW8595, ETBW8684, ETBW9554, ETBW8991 and ETBW9561 recorded bi value of unity and $S^{2}$ di value of closer to zero and were therefore showed broad or wide stability. Likewise, ETBW8595, ETBW9554 and ETBW8991 showed superior performance in seed yield (5.1 to $\left.5.2 \mathrm{t} \mathrm{ha}^{-1}\right)$ and broad adaptability and therefore these three genotypes were the most promising bread wheat genotypes based on Eberhart and Russell (1966) stability model. Similar findings have been reported by several authors (Akura et al., 2005; Akcura et al., 2006; Mohammadi et al., 2012; Abd El-Shafi et al., 2014; Changizi et al., 2014; Yaghotipoor et al., 2017; Gadisa and Abebe, 2020).

\subsection{Shuckla's stability variance (ri2)}

Shuckla (1972) proposed the variance component of each genotype across environments as measure of phenotypic stability. Based on the residuals in a two-way classification, the variance of a genotype across environments is the stability measure. According to Shuckla stability variance (ri2) $\mathrm{GxE}$ sum of squares is partitioned into components, one corresponding to each genotype (Shuckla, 1972). If the stability variance of a genotype is equal to environmental variance (ri2=0) then the genotype is stable. A large value of ri2 illustrate that the genotype is unstable (Shuckla 1972; Fasahat et al., 2015). Accordingly, the following genotypes: ETBW8583, ETBW8595, ETBW8668, ETBW8684, ETBW8751, ETBW8858, ETBW8870, ETBW8991, ETBW9486, ETBW9555, ETBW9556, ETBW9558 and ETBW9561 were stable (Table 4). Among these genotypes ETBW8595, ETBW8668, ETBW8751, ETBW8870, ETBW8991 and ETBW9558 were stable as well as highest yielding bread wheat genotypes as they produced grain yield that ranged from 5.0 to $5.4 \mathrm{t} \mathrm{ha}^{-1}$. On the other hand, ETBW9547 and Hidase were found unstable genotypes. Similarly, Yaghotipoor et al. (2017) identified three stable and four unstable bread wheat genotypes by evaluating 20 bread wheat genotypes across six environments. Likewise, 


\begin{tabular}{|c|c|c|c|c|c|c|c|c|c|c|c|c|}
\hline \multirow[t]{2}{*}{ GEN } & \multirow[t]{2}{*}{ Mean } & \multicolumn{2}{|l|}{ Francis } & \multicolumn{2}{|l|}{$E \& R$} & \multirow{2}{*}{$\frac{\text { Shuckla }}{\mathrm{ri}^{2}}$} & \multicolumn{2}{|c|}{$P \& J$} & \multirow{2}{*}{$\frac{\mathrm{WE}}{\mathrm{Wi}}$} & \multirow{2}{*}{$\begin{array}{c}\mathrm{SM} \\
\mathrm{Pi}\end{array}$} & \multirow{2}{*}{$\frac{\text { NPN \& H }}{\operatorname{Si}(1)}$} & \multirow{2}{*}{$\begin{array}{c}* \\
\mathrm{Si}^{2} \\
\end{array}$} \\
\hline & & CV (\%) & $\mathrm{Bi}$ & $\mathrm{S}^{2} \mathrm{di}$ & $\mathrm{R}^{2}$ & & $\mathrm{Bi}$ & $\mathrm{DJi}$ & & & & \\
\hline ETBW 8583 & 4.8 & 33.56 & 0.961 & 0.130 & 0.84 & 0.42 & -0.04 & 0.44 & 7.10 & 3.84 & 0.77 & 50.76 \\
\hline ETBW 8595 & 5.1 & 32.97 & 1.015 & 0.142 & 0.85 & 0.43 & 0.01 & 0.45 & 7.24 & 3.21 & 1.18 & 53.79 \\
\hline ETBW 8668 & 5.1 & 30.12 & 0.926 & 0.109 & 0.84 & 0.41 & -0.07 & 0.42 & 6.92 & 3.10 & 0.65 & 30.60 \\
\hline ETBW 8684 & 4.7 & 36.89 & 1.049 & 0.121 & 0.86 & 0.41 & 0.05 & 0.43 & 7.00 & 3.92 & 0.75 & 65.25 \\
\hline ETBW 8751 & 5.4 & 33.35 & 1.107 & 0.041 & 0.90 & 0.35 & 0.11 & 0.35 & 6.07 & 2.41 & 1.03 & 44.47 \\
\hline ETBW 8802 & 4.5 & 29.78 & 0.776 & 0.063 & 0.80 & 0.48 & -0.22 & 0.37 & 7.98 & 4.23 & 1.22 & 71.72 \\
\hline ETBW 8804 & 3.7 & 39.32 & 0.787 & 0.375 & 0.69 & 0.78 & -0.21 & 0.68 & 12.76 & 6.54 & 0.71 & 56.35 \\
\hline ETBW 8858 & 4.9 & 36.67 & 1.124 & 0.023 & 0.90 & 0.35 & 0.12 & 0.33 & 5.95 & 2.89 & 1.22 & 68.12 \\
\hline ETBW 8862 & 5.0 & 38.04 & 1.128 & 0.299 & 0.84 & 0.63 & 0.13 & 0.61 & 10.40 & 3.80 & 1.18 & 74.54 \\
\hline ETBW 8870 & 5.0 & 35.65 & 1.150 & -0.227 & 0.98 & 0.11 & 0.15 & 0.08 & 2.23 & 3.14 & 0.82 & 34.59 \\
\hline ETBW 8991 & 5.2 & 32.45 & 1.023 & 0.109 & 0.86 & 0.40 & 0.02 & 0.42 & 6.73 & 2.98 & 0.93 & 62.07 \\
\hline ETBW 8996 & 5.1 & 29.32 & 0.845 & 0.327 & 0.74 & 0.67 & -0.15 & 0.64 & 11.14 & 3.13 & 1.10 & 66.43 \\
\hline ETBW 9486 & 4.5 & 41.60 & 1.159 & 0.039 & 0.91 & 0.39 & 0.16 & 0.35 & 6.59 & 4.52 & 1.02 & 60.06 \\
\hline ETBW 9547 & 5.1 & 45.49 & 0.688 & 4.203 & 0.21 & 4.77 & -0.31 & 4.51 & 76.09 & 1.78 & 1.21 & 63.66 \\
\hline ETBW 9548 & 4.6 & 42.32 & 1.141 & 0.417 & 0.82 & 0.76 & 0.14 & 0.73 & 12.42 & 4.23 & 1.04 & 74.21 \\
\hline ETBW 9549 & 4.3 & 38.23 & 0.933 & 0.386 & 0.76 & 0.69 & -0.07 & 0.70 & 11.31 & 4.71 & 0.99 & 59.90 \\
\hline ETBW 9550 & 4.1 & 42.36 & 1.052 & 0.206 & 0.84 & 0.50 & 0.05 & 0.52 & 8.37 & 5.20 & 0.80 & 32.07 \\
\hline ETBW 9551 & 4.3 & 43.58 & 1.109 & 0.443 & 0.80 & 0.76 & 0.11 & 0.75 & 12.53 & 4.60 & 0.87 & 83.07 \\
\hline ETBW 9552 & 4.0 & 45.57 & 1.071 & 0.290 & 0.83 & 0.59 & 0.07 & 0.60 & 9.80 & 5.29 & 1.03 & 62.12 \\
\hline ETBW 9553 & 5.1 & 37.21 & 1.053 & 0.752 & 0.72 & 1.05 & 0.05 & 1.06 & 17.11 & 3.23 & 0.84 & 62.00 \\
\hline ETBW 9554 & 5.2 & 33.30 & 1.042 & 0.201 & 0.84 & 0.49 & 0.04 & 0.51 & 8.25 & 2.79 & 0.79 & 45.53 \\
\hline ETBW 9555 & 4.3 & 36.19 & 0.948 & -0.018 & 0.88 & 0.27 & -0.05 & 0.29 & 4.79 & 4.71 & 0.76 & 37.06 \\
\hline ETBW 9556 & 4.8 & 37.10 & 1.094 & 0.020 & 0.90 & 0.33 & 0.09 & 0.33 & 5.63 & 3.59 & 0.88 & 55.37 \\
\hline ETBW 9557 & 4.9 & 35.97 & 0.977 & 0.611 & 0.72 & 0.90 & -0.02 & 0.92 & 14.76 & 3.97 & 0.97 & 88.41 \\
\hline ETBW 9558 & 5.0 & 35.71 & 1.115 & -0.085 & 0.93 & 0.23 & 0.12 & 0.22 & 4.12 & 3.15 & 0.97 & 47.82 \\
\hline ETBW 9559 & 4.6 & 41.82 & 1.086 & 0.655 & 0.75 & 0.96 & 0.09 & 0.96 & 15.73 & 4.61 & 1.25 & 86.59 \\
\hline ETBW 9560 & 4.8 & 31.11 & 0.862 & 0.223 & 0.78 & 0.56 & -0.14 & 0.53 & 9.28 & 3.81 & 1.13 & 69.12 \\
\hline ETBW 9561 & 4.6 & 34.17 & 0.955 & 0.083 & 0.85 & 0.37 & -0.05 & 0.39 & 6.37 & 4.11 & 0.84 & 47.82 \\
\hline Hidasse & 4.6 & 49.26 & 0.921 & 2.982 & 0.39 & 3.31 & -0.08 & 3.29 & 52.91 & 5.62 & 1.21 & 109.53 \\
\hline Wane & 4.8 & 33.93 & 0.903 & 0.505 & 0.71 & 0.82 & -0.10 & 0.81 & 13.41 & 3.84 & 1.11 & 81.16 \\
\hline
\end{tabular}

E \& R: Eberhart \& Russell; P \& J: Perkins \& Jinks; WE: Wricke's Ecovalence; SM: Superiority measure; NPN \& H: Non parametric Nassar \& Huehn; Where, GEN=Genotypes; CV=Coefficient of variation; bi=regression coefficient; $\mathrm{S}^{2}$ di=deviation from regression; $\mathrm{R}^{2}=$ Coefficient of determination; $\mathrm{ri}^{2}=$ =stability variance; $\mathrm{Bi}=$ adjusted linear regression coefficient and deviation; $\mathrm{Wi}=$ genotypic eccovalence; $\mathrm{Pi}=$ Superiority Index measure; $\mathrm{Si}(1)$ and $\mathrm{Si}^{2}=$ nonparametric stability statistics.

Akcura et al. (2006) identified seven stable durum wheat genotypes among 15 genotypes evaluated across eight environments.

\subsection{Lin and Binns' Pi, stability model}

According to Lin and Binns (1988), each genotype's performance is assessed by a superiority measure (its $P i$ value), defined as the distance mean square between the genotype's response and the maximum response averaged over all environments (Lin and Binns, 1988). $\mathrm{Pi}$ is the mean square distance between the genotypes response and the maximum response at all locations (Mohammadi et al. 2012). Small Pi value indicates less distance between the 
ith genotype and the genotype with maximum performance and the better the genotype. A low Pivalue indicates high stability.

Based on the superiority index ( $\mathrm{Pi}$ ) measure (Lin and Binns, 1988), a genotype is stable if it has a low $\mathrm{Pi}$ (Kilic, 2010). In this case, ETBW 9547, ETBW8751, ETBW9554, ETBW8858, ETBW8991, ETBW8595, ETBW8996, ETBW8870, ETBW9558, ETBW8595 and ETBW9553 were the most stable genotypes (Table 4). Likewise, listed genotypes produced superior grain yield. On the other hand, ETBW8804, Hidase, ETBW9552, ETBW9550, ETBW9549, ETBW9555, ETBW9559, ETBW9551 and ETBW9486 were unstable bread wheat genotypes. Besides, these genotypes are low yielders. Pi stability model indicated not only genotypic stability but also crop performance. Similar findings have been reported by Gadisa et al. (2021) by evaluating 15 bread wheat varieties in 21 environments in Ethiopia. Mohammadi et al. (2012) also identified three bread wheat genotypes that were superior yielders as well as stable by evaluating 18 bread wheat genotypes across wide environments.

\subsection{Wricke's (1962) ecovalence $\left(W^{2} i\right.$ :}

The GE interaction effects for genotype $\mathbf{i}$, squared and summed across all environments, is the stability measure for genotype i. Genotypes with a low value of $\mathrm{W}^{2} \mathrm{i}$ have smaller deviations from the mean across environments and are therefore more stable. Ecovalence indicates the contribution of each genotype to GEI (Wricke, 1962). The varieties with lowest ecovalence contributed the least to GEI and are therefore more stable (Abd El-Shafi et al., 2014). Using Wricke (1962) stability parameter bread wheat genotypes namely ETBW8870, ETBW9558, ETBW9555, ETBW9556, ETBW8858, ETBW8751, ETBW9561, ETBW9486, ETBW8991, and ETBW8668 with low ecovalence were stable as they contributed the least to GEI (Table 4). Among these genotypes ETBW8870, ETBW9558, ETBW8751, ETBW8991 and ETBW8668 were stable and highest yielders for they produced 5.0 to $5.4 \mathrm{t} \mathrm{ha}^{-1}$ grain yield (Table 4). Likewise, other researchers Abd El-Shafi et al. (2014); Yaghotipoor et al. (2017) identified three stable and four unstable bread wheat genotypes separately, by using Wricke stability model, by evaluating 10 and 20 bread wheat genotypes across eight and six environments, respectively. Similar findings were also reported by Akcura et al. (2006). However, ETBW9557, ETBW9559, and ETBW9553 were unstable. Besides, genotypes like ETBW9547 and Hidase were the most unstable and had the highest contribution to the GEI.

\subsection{Pinthus stability model}

Pinthus (1973) introduced coefficient of determination $\left(\mathrm{R}^{2} \mathrm{i}\right)$ method to estimate stability of genotypes. He suggested
$\mathrm{R}^{2} \mathrm{i}$ as an alternative to deviation mean squares. Higher $\mathrm{R}^{2} \mathrm{i}$ values are desired because illustrate favorable responses to environmental variations (Fasahat et al., 2015). The coefficient of determination is often considered a better index for measuring the validity of the linear regression than $\mathrm{S}^{2} \mathrm{di}$, because its value ranges between zero and one (Abd El-Shafi et al., 2014; Fasahat et al., 2015). Bilbro and Ray (1976) suggested that $\mathrm{R}^{2} \mathrm{i}$ could be useful in measuring dispersion around the regression line and therefore related to the predictability and repeatability of the performance within environments. In the present studies, based on coefficient of determination the following bread wheat genotypes: ETBW8870, ETBW9558, ETBW9486, ETBW9556, ETBW8858, ETBW8751, ETBW9555, ETBW8991, ETBW8684, ETBW9561 and ETBW8591, whose $\mathrm{R}^{2} \mathrm{i}$ value vary from $85 \%$ to $98 \%$, were found stable (Table 4). Similarly, Abd El-Shafi et al. (2014) identified five bread wheat genotypes that showed linear response across environments by evaluating 10 bread wheat genotypes across eight environments. On the contrary, ETBW9547 and Hidase were the most unstable for they recorded $\mathrm{R}^{2} \mathrm{i}$ value below 40\%. Besides, ETBW8804, Wane, ETBW9553, ETBW9557 and ETBW8996 were also unstable genotypes for their $\mathrm{R}^{2} \mathrm{i}$ values were below 75\% (Table 4). Yet, Yaghotipoor et al. (2017) identified all evaluated 20 bread wheat genotypes as stable.

\subsection{Nassar and Huehn stability model}

According to Nassar and Huehn (1987) two rank stability measures Si1 and Si2 were proposed and based on the ranks of the genotypes across the environments and they gave equal weight to each environment. For a genotype with a maximum stability $(\mathrm{Si} 1=0) \mathrm{Si} 2$ gives the variance among the ranks across environments. Zero variance is an indication of maximum stability. Accordingly, ETBW8583, ETBW8668, ETBW8751, ETBW8804, ETBW8870, ETBW9549, ETBW9550, ETBW9554, ETBW9555, ETBW9556, ETBW9558 and ETBW9561 gave smaller values, thus they were considered as the most stable (Table 4). Out of these genotypes ETBW8668, ETBW8751, ETBW8870, ETBW9554 and ETBW9558 produced the highest grain yield ( 5.0 to $\left.5.4 \mathrm{tha}^{-1}\right)$. Therefore, these five bread wheat genotypes were the most stable and desirable. On the other hand, ETBW8802, ETBW8858, ETBW8862, ETBW9559, ETBW9560, Hidase and Wane gave larger values, thus they were unstable as well as low yielders except ETBW8862 (Table 4). Similar results were reported by (Yaghotipoor et al., 2017).

\subsection{Perkins and Jinks}

Based on Perkins and Jinks (1968) methods of stability analysis ETBW8583, ETBW8595, ETBW8991, ETBW9550, ETBW9553, ETBW9554, ETBW9555, 
ETBW9557 and ETBW9561 were the most stable. Out of these genotypes four bread wheat genotypes namely ETBW8595, ETBW8991, ETBW9553 and ETBW9554 were the highest yielding (5.1 to $5.2 \mathrm{t} \mathrm{ha}^{-1}$ ) and the most stable (Table 4). On the other hand, ETBW8802, ETBW8804, ETBW8870, ETBW8996, ETBW9486 and ETBW9547 were unstable. Yet, ETBW9547 and ETBW8996 produced highest yield $\left(5.1 \mathrm{t} \mathrm{ha}^{-1}\right)$, therefore, these two genotypes were only suitable for an optimal environmental conditions. Similar results were reported by Syukur et al. (2011).

3.10. Reaction of promising and advanced bread wheat genotypes to wheat stem rust and yellow rust

Stem and yellow rusts caused by Puccinia sp. are major production constraints in Ethiopia as they are able to cause total yield losses. Several popular bread wheat varieties were devastated due to these pathogens outbreaks during 200910 and 2013-14 and continued to be major threat to bread wheat production and productivity since then in major wheat growing zones of Ethiopia. Use of improved varieties with durable rust resistance is number one rust management option with economical and environmental feasibility. Thus, identified high yielding, stable, adaptable, rusts resistant advanced bread wheat genotypes (Table 5) could be an option for million resource poor and needy wheat farmers in Ethiopia. Besides, these genotypes can also be included in multipurpose crossing blocks in order to further improve commercial and elite bread wheat genotypes and further benefit farmers, agro-industries and consumers at large.

Table 5: Reaction of promising bread wheat genotypes to SR and YR diseases

\begin{tabular}{|c|c|c|c|c|c|}
\hline GEN & $\begin{array}{l}\text { YLD } \\
\left(\mathrm{t} \mathrm{ha}^{-1}\right)\end{array}$ & $\begin{array}{c}\text { YR (Severity } \\
\%+\text { Reaction) Mean }\end{array}$ & $\begin{array}{c}\text { YR (Severity } \\
\%+\text { Reaction) Range }\end{array}$ & $\begin{array}{c}\text { SR (Severity } \\
\%+\text { Reaction) Mean }\end{array}$ & $\begin{array}{c}\text { SR (Severity } \\
\%+\text { Reaction) Range }\end{array}$ \\
\hline Wane & 4.8 & 5MRMSS & 0-20MSS & $2 \mathrm{MSS}$ & $0-10 \mathrm{MSS}$ \\
\hline ETBW8595 & 5.1 & 4MRMS & 0-15MRMS & 11MSS & $0-60 \mathrm{~S}$ \\
\hline ETBW8668 & 5.1 & 4MRMS & 0-15MRMS & $12 \mathrm{MSS}$ & $0-50 \mathrm{~S}$ \\
\hline ETBW8751 & 5.4 & 3MRMS & 0-10MRMS & 4MRMS & 0-15MSMR \\
\hline ETBW8862 & 5.0 & 2MRMS & 0-10MRMS & 4MRMS & 0-15MRMS \\
\hline ETBW8870 & 5.0 & 5MRMS & 0-15MSMR & 3MRMS & 0-10MRMS \\
\hline ETBW8996 & 5.1 & 5MRMSS & 0-20MSS & 4MSS & 0-20MSS \\
\hline ETBW9547 & 5.1 & 2MRMS & 0-10MSMR & 1MRMS & 0-5MRMS \\
\hline ETBW9553 & 5.1 & 7MRMS & 0-15MRMS & 2MRMS & 0-5MRMS \\
\hline ETBW9554 & 5.2 & 7MRMS & 0-15MRMS & 1MRMS & 0-5MRMS \\
\hline ETBW9558 & 5.0 & 10MSS & $0-50 \mathrm{~S}$ & trMR & 0-1MR \\
\hline Hidase & 4.6 & 19MSS & $0-60 \mathrm{~S}$ & 37MSS & $0-80 \mathrm{~S}$ \\
\hline
\end{tabular}

Where, GEN: Genotype; YLD ( $\left.\mathrm{t} \mathrm{ha}^{-1}\right)$ : Grain Yield in $\mathrm{t} \mathrm{ha}^{-1}$; YR: Yellow rust; SR: Stem rust; MR: Moderately Resistant; MS: Moderately Susceptible; S: Susceptible; Remark: YR and SR severity and reaction means were analyzed based on 2018-19 data at seven locations

\section{CONCLUSION}

$\mathrm{E}$ ight bread wheat genotypes ETBW8595, ETBW8668, ETBW8751, ETBW8991, ETBW8996, ETBW9547, ETBW9553 and ETBW 9554 produced grain yield of more than $5.0 \mathrm{tha}^{-1}$, indicating their superior yielding potential. ETBW8595, ETBW8668, ETBW8751, ETBW8991 and ETBW9554 were found the most stable bread wheat genotypes as confirmed by five to eight stability models. ETBW8751, ETBW8991 and ETBW9554 were highest yielding, stable, resistant and moderately resistant to prevailing stem and yellow rust diseases. Hence, ETBW8751, ETBW8991 and ETBW9554 shall be verified and released.

\section{ACKNOWLEDGEMENT}

$\triangle$ uthors would like to gratefully acknowledge the

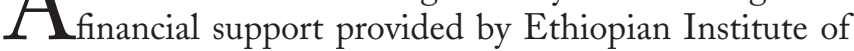
Agricultural Research and Kulumsa Agricultural Research Center to conduct the present studies. Besides, we gratefully acknowledge Wheat Research Programs of Collaborating Research Centers namely Holetta, Debrezeit, Adet, Areka, Debrebirhan and Bako for their keen support in field experiments execution, management and data collection.

\section{REFERENCES}

Abd El-Shafi, M.A., Gheith, E.M.S., Abd El-Mohsen, A.A., Suleiman, H.S., 2014. Stability analysis and 
correlations among different stability parameters for grain yield in bread wheat. Scientia Agriculturae 6(3), 135-140.

Akcura, M., Kaya, Y., Taner, S., Ayranci, R., 2006. Parametric stability analyses for grain yield of durum wheat. Plant Soil Environment 52(6), 254-261.

Akura, M., Kaya, Y., Taner, S., 2005. Genotypeenvironment interaction and phenotypic stability analysis for grain yield of durum wheat in the central anatolian region. Turkish Journal of Agriculture 29, 369-375.

Asghar, A., Saeed, R., Shahid, N., Abdul, N., Aziz-ur, R., 2011. Utilization of wheat species as cultural food. In: Maria, T.A. (Ed.) Wheat: genetics, crops and food production. Nova Science Publishers, Inc.

Asrat, A., Fistum, A., Fekadu, G., Mulugeta, A., 2009. AMMI and SREG GGE biplot analysis for matching varieties onto soybean production environments in Ethiopia. Scientific Research and Essay 4(11), 1322-1330.

Becker, H.B., Leon, J., 1988. Stability analysis in plant breeding. Plant Breeding 101, 1-23.

Bilbro, J.D., Ray, I.L., 1976. Environmental stability and adaptation of several cotton cultivars. Crop Science 16, 821-824.

Charmet, G., 2011. Wheat domestication: Lessons for the future. Comptes Rendus Biologies 334, 212-220.

Changizi, M., Rajab, C., Eslam, M.H., Mohammad, R.B., Farrokh, D., 2014. Evaluation of genotype_ environment interaction and stability of corn hybrids and relationship among univariate parametric methods. Canadian Journal of Plant Sciences 94, 1255-1267.

CSA (Central Statistical Agency), 2020. Report on area and production of major crops (private peasant holdings, meher season). Volume I. Statistical Bulletin 587. https://instepp.umn.edu/sites/instepp.umn.edu/files/ product/downloadable/Ethiopia_2019-0_vol_1.pdf accessed on May12, 2021.

Curtis, B.C., Rajaram, S., Gomez, M.H., 2002. Bread wheat improvement and production. FAO Plant Production and Protection Series No. 30. https:// fao.org/3/y4011e/y4011e00.htm accessed on July 22, 2021.

Dawit, A.T., Zerihun, T., Habtemariam, Z., Alemayehu, A., 2017. Seasonal variability and genetic response of elite bread wheat lines in drought prone environments of Ethiopia. Journal of Plant Breeding and Genetics 05(01), 15-21.

Ebdon, J.S., Gauch, H.G., 2002. Additive main effect and multiplicative interaction analysis of national turf-grass performance trials. Crop Science 42, 489-496.
Eberhart, S.A., Russel, A.W., 1966. Stability parameters for comparing varieties. Crop Science 6, 36-40.

Farshadfar, E., Sadeghi, M., 2014. GGE Biplot Analysis of genotypexenvironment interaction in wheatagropyron disomic addition lines. Agricultural Communications 2(3), 1-7.

Fasahat, P., Rajabi, A., Mahmoudi, S.B., 2015. An overview on the use of stability parameters in plant breeding. Biometrics and Biostatistics International Journal 2(5), 149-159.

Ferreira, D.F., Clarice, G.B.D., Bryan, F.J.M., Amauri de, A.M., Roland, V., 2006. Statistical models in agriculture: biometrical methods for evaluating phenotypic stability in plant breeding. Cerne, Lavras 12(4), 373-388.

Finlay, K.W., Wilkinson, G.N., 1963. The analysis of adaptation in a plant-breeding programme. Australian Journal of Agricultural Research 14, 742-754.

Fransis, T.R., Kannenberg, L.W., 1978. Yield stability studies in short-season maize. I. A descriptive method for grouping genotypes. Canadian Journal of Plant Sciences 58, 1029-1034.

Gadisa, A.W., Abebe, D.A., 2020. Evaluation of grain yield stability analysis in bread wheat (Triticum aestivum L.) genotypes using parametric method. American Journal of Life Sciences 8(6), 189-195.

Gadisa, A., Alemu, D., Nagesh, G., Ruth, D., Tafesse, S., Habtemariam, Z., Abebe, G., Abebe, D., Dawit, A., Bayisa, A., Yewubdar, S., Bekele, G.A., Ayele, B., 2021. Genotypexenvironment interaction and selection of high yielding wheat genotypes for different wheat-growing areas of Ethiopia. American Journal of Bio-Science 9(2), 63-71.

Gadisa, A., Negash, G., Alemu, D., Abebe, D., Tefasse, S., Rut, D., 2021. Stability models for selecting adaptable and stable bread wheat (Tritium aestivum $\mathrm{L}$.) varieties for grain yield in Ethiopia. Journal of Agricultural Science and Engineering 7(1), 14-22.

Gauch, H.G., 2006. Statistical analysis of yield trials by AMMI and GGE. Crop Science 46, 1488-1500.

Haas, M., Schreiber, M., Mascher, M., 2018. Domestication and crop evolution of wheat andbarley: Genes, genomics, and future directions. Journal of Integrative Plant Biology 61(3), 204-225.

Habte, D., Tadesse, K., Admasu, W., Desalegn, T., Mekonen, A., 2014. Agronomic and economic evaluation of the $\mathrm{N}$ and $\mathrm{P}$ response of bread wheat growing in the moist and humid mid highland vertisols areas of Arsi zone, Ethiopia. African Journal of Agricultural Research 10, 89-99.

Hodson, D.P., Jaleta, M., Tesfaye, K., 2020. Ethiopia's transforming wheat landscape: tracking variety 
use through DNA fingerprinting. Scientific Reports 10, 18532.

Jeberson, M.S., Kant, L., Kishore, N., Rana, V., Walia, D.P., Singh D., 2017. AMMI and GGE biplot analysis of yield stability and adaptability of elite genotypes of bread wheat (Triticum aestivum L.) for Northern hill zone of India. International Journal of Bio-resource and Stress Management 8(5), 635-641.

Kaya, Y., Palta, C., Taner, S., 2002. Additive main effects and multiplicative interactions analysis of yield performances in bread wheat genotypes across environments. Turkish Journal of Agriculture 275-279.

Kilic, H., Akura, M., Aktas, H., 2010. Assessment of parametric and non-parametric methods for selecting stable and adapted durum wheat genotypes in multienvironments. Notulae Botanicae Horti Agrobotanici Cluj-Napoca 38(3), 271-279.

Lin, C.S., Binns, M.R., 1988. A superiority measure of cultivar performance for cultivar location data. Canadian Journal of Plant Sciences 68, 193-198.

MoANR (Ministry of Agriculture and Natural Resource), 2016. Plant variety release, protection and qualuty control directorate. Crop Variety Register. Issue No. 19. Addis Ababa, Ethiopia.

Mohammadi, M., Karimzadeh, R., Sabaghnia, N., Shefazadeh M.K., 2012. Genotype environment interaction and yield stability analysis of new improved bread wheat genotypes. Turkish Journal of Field Crops $17,67-73$.

Nassar, R., Huehn M., 1987. Studies on estimation of phenotypic stability: Tests of significance for nonparametric measures of phenotypic stability. Biometrics 43, 45-53.

Nelson, G.C., Rosegrant, M.W., Palazzo, A., Gray, I., Ingersoll, C., Robertson, R., Tokgoz, S., 2010. Food security, farming, and climate change to 2050: Scenarios, results, policy options. Washington: IFPRI.

Olivera, P., Newcomb, M., Szabo, L.J., Rouse, M., 2015. Phenotypic and genotypic characterization of race TKTTF of Puccinia graminis $\mathrm{f}$. sp. tritici that caused a wheat stem rust epidemic in southern Ethiopia in 2013-14. Phytopathology 105(7), 917-928.

Pacheco, A., Vargas, M., Alvarado, G., Rodriguez, F., Crossa, J., Burgueno, J., 2016. GEA-R (GenotypexEnvironment analysis with $\mathrm{R}$ for Windows) Version 4.0, CIMMYT Research Data and Software Repository Network.

Perkins, J.M., Jinks, L.J., 1968. Environmental and genotype environmental components of variability. III. Multiple lines and crosses. Heredity 23, 339-356. Pinthus, M.J., 1973. Estimate of genotypic value: A proposed method. Euphytica 22, 345-351.

Purchase, J.L., 1997. Parametric analysis to describe genotype by environment interaction and yield stability in winter wheat. PhD Thesis, Department of Agronomy at the University of Orange Free State, Bloemfontein.

Rosegrant, M.W., Agcaoili, M., 2010. Global food demand, supply, and price prospects, International Food Policy Research Institute, Washington, DC.

Shewry, P.R., Sandra, J.H., 2015. The contribution of wheat to human diet and health. Food and Energy Security 4(3), 178-202.

Singh, R.P., Hodson, D.P., Jin, Y., 2015. Emergence and spread of new races of wheat stem rust fungus: continued threat to food security and prospects of genetic control. Phytopathology 105(7), 872-884.

Shiferaw, B., Smale, M., Braun, H.J., 2013. Crops that feed the world 10. Past successes and future challenges to the role played by wheat in global food security. Food Security 5, 291-317.

Shukla, G.K., 1972. Some statistical aspects of partitioning genotype-environmental components of variability. Heredity 29, 237-245.

Singh, C., Arun, G., Vikas, G., Pradeep, K., Sendhil, R., Tyagi, B.S., Gyanendra, S., Ravish, C., Singh, G.P., 2019. Genotypexenvironment interaction analysis of multi-environment wheat trials in India using AMMI and GGE biplot models. Crop Breeding and Applied Biotechnology 19(3), 309-318.

Syukur, M., Sriani, S., Rahmi, Y., Darmawan, A.K., 2011. Parametric stability analysis for yield of chili pepper (Capsicum annuum L.). Indonesian Journal of Agronomy 39 (1), 31-37.

Temesgen, T., Keneni, G., Sefera, T., Jarso, M., 2015. Yield stability and relationships among stability parameters in faba bean (Vicia faba L.) genotypes. The Crop Journal 3(3), 258-268.

Tolemariam, A., Jaleta, M., Hodson, D., Alemayehu, Y., Yirga, C., Abeyo, B., 2018. Wheat varietal change and adoption of rust resistant wheat varieties in Ethiopia from 2009/10 to 2013/14. Socioeconomics Program Working Paper 12. Mexico, CDMX: CIMMYT.

Verma, A., Ravish, C., Indu, S., 2015. AMMI and GGE biplots for $\mathrm{G} \times \mathrm{E}$ analysis of wheat genotypes under rain fed conditions in central zone of India. Journal of Applied and Natural Science 7(2), 656-661.

Verma, A., Singh, G.P., 2021. Combining AMMI and mean yield of wheat genotypes evaluated under rainfed conditions of northern hills zone for stability analysis. International Journal of Bio-resource and Stress Management 11(6), 590-600. DOI: HTTPS://DOI. ORG/10.23910/1.2020.2162b 
Wricke, G., 1962. On a method of understanding the biological diversity in field research. Z. Pflanzenzucht 47, 92-96.

Yaghotipoor, A., Farshadfar, E., Saeidi, M., 2017. Evaluation of phenotypic stability in bread wheat accessions using parametric and non-parametric methods. The Journal of Animal \& Plant Sciences 27(4), 1269-1275.

Yan, W, 2011. GGE Biplot vs AMMI graphs for genotype by environment data analysis. Journal of the Indian Society of Agricultural Statistics 65(2), 181-193.
Yasin, R., Agdew, B., Yasin, G., 2014. GGE and AMMI biplot analysis for field pea yield stability in snnpr state, ethiopia. International Journal of Sustainable Agricultural Research 1(1), 28-38.

Zobel, R.W., Wright, M.J., Gauch, H.G., 1988. Statistical analysis of yield trial. Agronomy Journal 80, 388-393. 